\title{
LOS NEGROS Y LOS CUIDADOS EN LAS FAMILIAS DE BRASIL: UNA VISIÓN HISTÓRICA E ICONOGRÁFICA
}

\author{
Paulo Fernando de Souza Campos
}

Doctor en Historia. Post-Doutorando de la Escuela del Enfermería, Universidad de Sao Paulo. Miembro del Grupo Historia y Legislación de la Enfermería - ENO/EEUSP/CNPq. Becário FAPESP

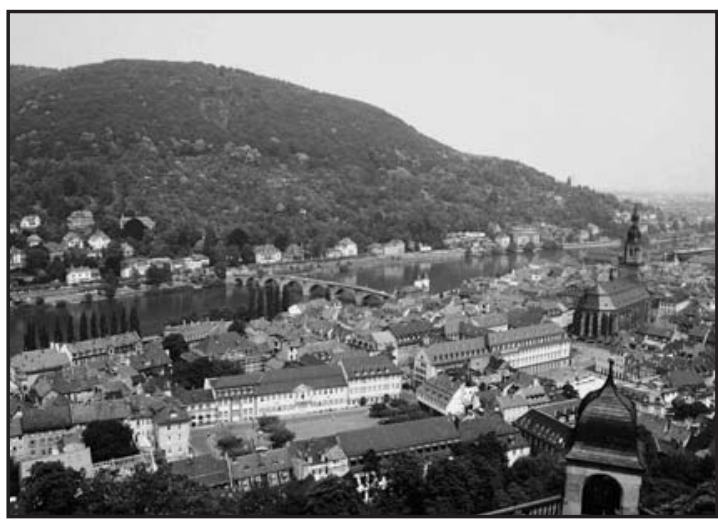

BLACKS AND HEALTH CARE IN BRAZILIAN FAMILIES: A HISTORICAL AND ICONOGRAPHIC VIEW

\section{SUMMARY}

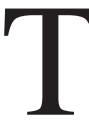

The present article offers a consideration of the social history in the art of caring. Considered in the long run the study allows us to assess certain facts performed by Brazilian women as first 'child minders'. Evidence comes by means of some photographs used as principal data and from which a cultural and a great interest about care constitutes a faithful debate and is clearly observed.

Outcomes indicate that Brazilian historiography on nursing and its main characters: 'nurses', have considered as nursing performances those practices of black women regarding their 'child minding' white families' children for generations up to the XX century. Practices considered effective among Brazilian culture and society, which continue up to the time being in small towns with limited health sources.

Key words: Women, nursing history, child minders
OS NEGROS E OS CUIDADOS NAS FAMÍLIAS DO BRASIL: UMA VISÃO HISTÓRICA E ICONOGRÁFICA

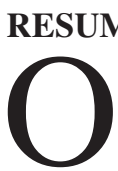

tigo objetiva uma reflexão da história social entorno da arte do cuidado. Reflexionada na dimensão do tempo largo da história, o estudo permite reconhecer feitos acerca das ações de mulheres negras no Brasil, o que possibilita considerá-las como as primeiras cuidadoras. Recuperadas por meio das fotografias, usadas como documentação principal, as evidências evocam um debate contundente e de grande interesse cultural do cuidado. Os resultados indicam que a historiografia brasileira, produzida sobre a enfermagem e seu principal personagem, as enfermeiras, desconsiderou ações de mulheres negras conhecidas por cuidar de crianças a gerações inteiras nas famílias brancas, até o século $\mathrm{XX}$, uma prática que resiste em lugares brasileiros mais afastados, em pequenas cidades, com poucos recursos à saúde, o que permite considerá-la efetiva na cultura e sociedade brasileira.

Palavras-chave: mulheres, história da enfermagem, cuidadoras de crianças.

\section{RESUMEN}

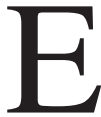
1 artículo objetiva una reflexión de la historia social en torno de la arte del cuidado. Reflexionada en la dimensión del largo tempo de la historia, el estudio permite reconocer hechos acerca de las acciones de mujeres negras en Brasil, lo que posibilita considerarlas como las primeras cuidadoras. Recuperado por intermedio de las fotografías, usadas como documentación principal, las evidencias evocan un debate contundente 
y de gran interes cultural del cuidado. Los resultados indican que la historiografía brasileña producida sobre la enfermería, y su principal personaje, las enfermeras, desconsideró acciones de mujeres negras conocidas por cuidar de niños a generaciones enteras en las familias blancas, hasta el siglo $\mathrm{XX}$, una práctica que resiste en sitios brasileños localizados a lejos, en pequeñas ciudades, con pocos recursos a la salud, lo que permite considerarla efectiva en la cultura y sociedad brasileña.

Palabras claves: mujeres; historia de la enfermería; cuidadoras de niños.

\section{INTRODUCCIÓN}

De acuerdo con las perspectivas de los escritos históricos, el análisis del pasado debe considerar el tiempo, el espacio y las características culturales que formalizan las relaciones en una determinada sociedad. Para eso, el trabajo del historiador debe asentarse en el uso de fuentes, registros que documentan los acontecimientos. Distanciada de la narrativa lineal, positivista, fundamentada en teorías herméticas, la (nueva) escritura de la historia lanzó preguntas al pasado, aproximando sus intereses y metodologías a otras ciencias y saberes.

A partir del análisis crítico de la historia, los historiadores se propusieron no contar más el qué y cuándo sucedieron las cosas, pero sí entender el porqué sucedieron las cosas, cómo se manifestaron los hombres y las mujeres, es decir, cómo vivían, se comportaban, cómo inventaban el cotidiano y daban significado a sus prácticas. Tal perspectiva historiográfica multiplicó los estudios interdisciplinarios cuyos abordajes, al evocar temas comunes, provocaron el encuentro de saberes distintos, pero con intereses convergentes. La transversalidad del conocimiento amplió el diálogo entre los saberes, revelándose imperioso para el desarrollo de la ciencia y la tecnología.

Los resultados de los estudios interdisciplinarios permitieron el reconocimiento del pasado no como algo concluido y acabado, sino a través de la dinámica que mueve la existencia humana, sus particularidades y diversidades. Así, evocar la larga historia de los cuidados y de los cuidadores, de la cual nos permite hablar Siles (1999), constituye los intereses del presente artículo.

\section{HISTORIA DE LA ENFERMERÍA BRASI- LEÑA}

En el Brasil, la historiografía dominante producida sobre la enfermería, se concentra en el análisis del poder simbólico conferido a la profesionalización. Centrada en la efervescencia de la Reforma Sanitaria de 1920 (movimiento sanitario, que reorganizó las políticas de salud brasileña, en las dos décadas iniciales del siglo XX) la historia de la enfermería evoca un contexto permeado por transformaciones sociales de gran relevancia, con especial atención en el paso de un trabajo esclavo a un trabajo libre, instituido a partir de la promulgación de la República, en 1889.

La mayoría de los estudios producidos sobre el tema, considera como marco original de la historia de la enfermería el trabajo ejecutado por Miss Ethel Parsons, enfermera norteamericana designada para (re)organizar la formación profesional de la enfermería en el Brasil. Por intermedio de la creación de la Escuela de Enfermeras del Departamento Nacional de Salud Pública - DNSP, órgano gubernamental que se encargó de las transformaciones en el campo de la salud en el año 1920, fue instituido como patrón de enseñanza la enfermería, mito fundador de la enfermería profesional brasileña.

Organizada en el Sistema Nightingale, el patrón impuesto, esencialmente femenino, no tuvo en cuenta prácticas de cuidar anteriores y agentes históricos que las ejecutaron durante cuatro siglos de esclavitud negra en el Brasil. Del mismo modo, los análisis emprendidos raramente consideraban las vicisitudes de las transformaciones sociales que construyeron la historia del Brasil como, por ejemplo, la utilización de la enfermería para difundir el american way of life, las cuestiones de género que feminizó la profesionalización y los problemas étnicos, en este caso, singular a la historia de la enfermería y cultura de los cuidados en el Brasil, en la medida en que los negros fueron, por excelencia, los primeros en ejercer el cuidado como trabajadores.

Las transformaciones sociales que distinguen el paso del Brasil Imperio al Brasil República eran caracterizadas a partir de la oficialidad de los registros emanados del centro. Las evidencias de experiencias anteriores no eran priorizadas por la investigación en historia de la enfermería en el Brasil. 
Los pocos vestigios que narran experiencias anteriores a la patronización de la enseñanza de enfermería, conocido como "patrón Anna Nery", aparecen desprestigiados y su contingente juzgado como "ignorante", sin preparación forjando el devenir histórico de la enfermería nacional.

Vista por ese ángulo, la historiografía dominante anuló la existencia de otros modelos asistenciales, como el modelo francés propuesto por el Dr. Bourneville (Espírito Santo, 2007), la existencia de espacios formadores de la enfermería anteriores a 1920, ejemplarmente la Escuela Profesional de Enfermeros y Enfermeras, fundada en 1890, actual Escuela de Enfermería Alfredo Pinto - EEAP, primera escuela de enfermería del Brasil (Moreira, 1999), así como la existencia de la Escuela de Enfermeras del Hospital Samaritano, en la ciudad de Sao Paulo, genuinamente nightingueliana (Mott, 1999; Carrijo, 2007). Sobre todo, las matrices clásicas de la historia de la enfermería brasileña no consideraban el contingente egresado del sistema esclavocrata, que actuaba como cuidador, así como la función social de los cuidados realizados en el ámbito de las familias y de las comunidades por las mujeres negras, como se pretende evidenciar.

La producción existente en el Brasil sobre la historia de la enfermería traduce abordajes clásicos, evocan temas como creación de escuelas, usos del modelo oficial de enseñanza, orientación religiosa y otros aspectos que recuperan biografías, trayectorias de mujeres, siempre ilustres, destacadas a nivel nacional, tales como las primeras líderes o las que participaron de movimientos sociales, como la Segunda Guerra Mundial. Aunque imprescindibles, se torna imperioso ampliar el debate, analizar el largo tiempo de la historia de la enfermería y percibirla en sus dimensiones culturales, antropológicas, como permite entrever la gestión transcultural de la enfermería propuesta por Leininger (1978).

El modelo de enseñanza preconizada como oficial para la enfermería brasileña hizo parte del proceso de expansión de la profesión como propia para mujeres, agregando un contingente eminentemente femenino, y que orienta el tema hacia el campo de la historia de las mujeres (Perrot, 2000; Oguisso, 2007, Secaf; Villas-Boas, 2007).

Los registros de ese proceso, con énfasis en la fotografía, son reveladores de problemáticas inter- nas, pues remontan adecuaciones, prácticas y representaciones sofocadas por el blanqueamiento de la memoria nacional, de la cual la enfermería es parte integrante. Así, esta comunicación esboza una reflexión en curso, a cerca de la particularidad y de la diversidad cultural de los cuidados en el Brasil, así como las rupturas y continuidades de ese proceso en la formación de la identidad profesional brasileña.

Sintomáticamente, la reciente publicación del libro Historia de la Enfermería Brasileña (Porto; Amorim, 2007), desveló la presencia de mujeres negras diplomadas por la primera escuela de enfermería profesional del Brasil, Escuela Profesional de Enfermeros y Enfermeras, anexada al Hospicio Nacional de Alienados, Río de Janeiro. La evidencia reitera que la exclusión de las mujeres negras de la enfermería profesional reiteraba la tendencia general que las identificaban como despreciables e impuras.

En ese sentido, abordar el tema por intermedio de las representaciones construidas para los negros en el Brasil se torna particularmente interesante. Estéticamente, el ideal de enfermera es representado por la imagen de la mujer joven, blanca, alta, saludable, elegante y culta. Las imágenes de la enfermera, idealizada como "ángel blanco", los patrones de belleza dominantes (piel clara, cabellos lacios y rubios) forjaban un imaginario que no concordaba con la realidad estética de la mayoría de las mujeres brasileñas, negando esencialmente el mestizaje y la multiculturalidad nacional.

La supervalorización del blanco escondía la realidad de los hechos: matrimonios inter-étnicos permanecían en escala creciente, a escondidas, en rebeldía a los padres, blancos y negros. Las relaciones inter-étnicas establecían estrechos límites de convivencia comunitaria, reproduciendo un segregacionismo rutinario, común y habitual. La Abolición de la Esclavitud, en 1888, asociada al proceso inmigratorio subsecuente, transformó las relaciones sociales, estableció la ciudadanía y la condición de igualdad de derechos entre los brasileños, blancos y negros.

Con todo, las órdenes médicas y normas familiares, prescritas como saludables e higiénicas, como única vía para la buena salud y el vigor físico que caracterizaban al hombre evolucionado, reiteraban proposiciones biotipológicas, clasificato- 
rias y deterministas, que desprestigiaban prácticas distintas a las propuestas por los manuales del buen vivir, copiados de segunda mano del mundo europeo.

Largamente utilizadas, las proposiciones médicas que imprimían civilidad y dictaban los códigos del buen ciudadano, imprimían una visibilidad social negativa a los hombres y mujeres negros, representándolos como degenerados, comprometidos física y moralmente, como si éstos fuesen naturalmente propensos a los desvíos y al libertinaje. Los significados sociales de las representaciones médicas identificaban a los negros como corrompidos biológicamente, cuyas personalidades monstruosas los conducirían a una vida marginal. Solamente en la década de 1950 la representación del negro como "asesino", "sádico", "necrófilo", "pervertido", pierde la fuerza sin desaparecer del imaginario social (Domingues, 2000; Santos, 2002; Holfbauer, 2002).

\section{REPRESENTACIONES DE LA ENFERME- RÍA BRASILEÑA}

El análisis histórico-cultural de las representaciones de la enfermería, aunque recurrente, ha sido poco estudiada en el ámbito de la investigación en enfermería en el Brasil. Particularmente interesada por el tema, Hallan (2000) estudió los efectos de las imágenes de la enfermería y de su principal personaje, la enfermera. Sus análisis privilegiaron las construcciones de imagen de la profesión, revela-

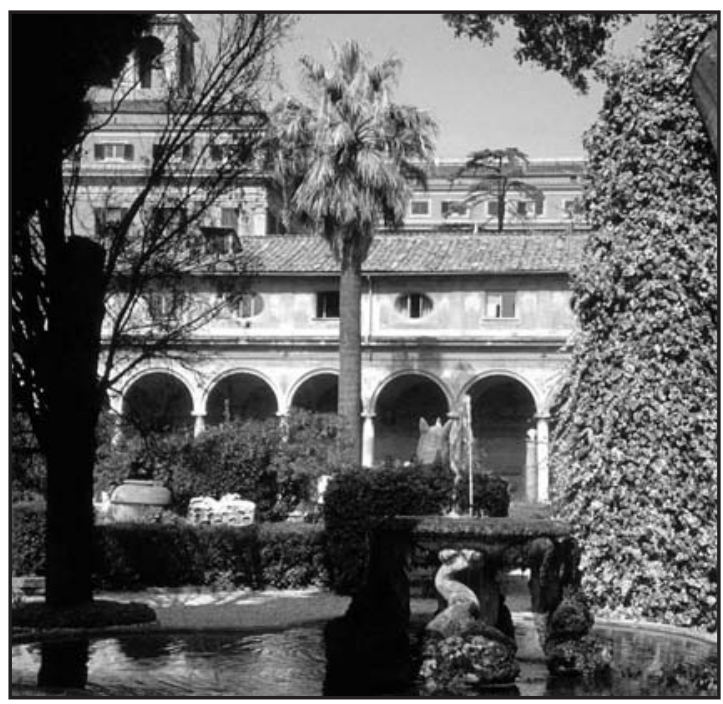

das por los mas media y por la cultura, así como el modo en que ellas interfirieron en la formación de la identidad profesional de la enfermería norteamericana.

En el Brasil, al destacar las circunstancias del advenimiento de la enfermería moderna, Barreira (1997) revela cómo el modelo de enfermería, asumido en la efervescencia de la Reforma Sanitaria de 1920, evaluaba la cuestión racial. Al analizar los procesos que condujeron la "implantación de la nueva profesión" la autora permite considerar que las representaciones construidas sobre los negros interfirieron en la formación de la identidad profesional.

Al evocar los inicios de la enfermería en el Brasil, específicamente a la Escuela de Enfermeras del Departamento Nacional de Salud Pública, posteriormente denominada Escuela de Enfermería Anna Nery, la autora evidencia “...varias de las candidatas que atendieron a las apelaciones humanitarias y patrióticas de los médicos sanitaristas provenían de la clase media alta de la sociedad, muchas de ellas habiendo sido directamente reclutadas por ellos. No obstante, las candidatas oriundas de familias pobres podrían ser bien recibidas, sin embargo lo mismo no ocurriría con las candidatas negras..." (Barreira, 1997, p. 168-69).

Del mismo modo, al analizar las influencias norteamericanas en la institucionalización de la enfermería brasileña, Castro Santos y Faria (2004, p. 142) afirman que la cuestión de la "raza" (en lo que concierne a la historia de la enfermería en el Brasil) "debe ser investigada a fondo". Sus argumentos reafirman la poca producción académica existente sobre el tema, mas sugiere, que desde el punto de vista racial, los incentivos e inversiones en la formación profesional propiciaron la movilidad social y ascenso de negros “... sin embargo sólo después de los primeros tiempos de formación de los cuadros dirigentes...".

La cristalización de las imágenes producidas para el negro en el Brasil, que los asociaban a las clases peligrosas, marcó profundamente las relaciones sociales entre blancos y negros. Asimilados como primitivos en la "fase evolutiva de la especie humana", hombres y mujeres negros eran excluidos de la participación más amplia de la sociedad, estigmatizados por la diseminación de estereotipos que no se afinaban con la imagen propuesta como 
ideal social, tampoco como ideal de enfermera, estratégicamente creada para la "nueva profesional".

Transpuesto para la enfermería, las representaciones del negro eran diametralmente opuestas a la elaborada como modelo de "enfermera patrón", que evocaba la imagen de la mujer blanca, rica, joven y culta; aunque las negras existiesen como cuidadoras en hospitales, en las Santas Casas de Misericordia. Transformados en prácticas, las representaciones localizaban en la inmensa parcela de la población nacional la forma acabada de la corrupción: la degeneración de la raza.

Para tal, políticamente, era imperioso vetar la posibilidad de que las negras ingresen en la enfermería patrón. Del mismo modo, la imposición del patrón pretendió anular de la memoria histórica acciones de cuidadoras negras, amamantadoras, cuidadoras de niños, negras viejas, mujeres que cuidaban de gestantes, puérperas y niños, del parto al amamantamiento, consideradas esenciales.

La negación de la memoria afectiva de las cuidadoras negras encuentra su punto culminante en la década de 1920. La perspectiva antropológica italiana, asumida como fundamento teórico de la identificación de los desviados sociales, favoreció a la desaparición de la amamantadora. Tributaria de los dogmas de Cesare Lombroso, la antropometría pretendía identificar tipos criminales a partir de la identificación de trazos comunes, morfológicos o anatómicos. La clasificación de los biotipos posibilitaría la detección del desviado antes que éste delinca, forjando una actuación profiláctica, como proponía el discurso científico fundado en la medicina-eugénica.

Considerados por los "desvíos morales característicos de la raza", los negros eran vistos como comprometedores del proyecto republicano, impropios para asumir las funciones del mundo del trabajo, como era el caso de la enfermería profesional (Souza Campos, 2007).

De este modo, los acontecimientos vividos en las primeras décadas del siglo XX permiten interpretar modificaciones en el conjunto de las relaciones de poder-saber reorganizadoras del Brasil. Si en los períodos anteriores (Brasil Colonia, Brasil Imperio) el país era pensado como atrasado y su visibilidad diseminada por los símbolos del exilio, por la idea de paraíso y por las utopías de lo extra- ordinario, en la República, estas imágenes asumen una armazón científica, pautada en el positivismo evolucionista que caracterizó a la ciencia en el paso del siglo XVIII al XIX.

La representación del país como un lugar de incivilidad, imperfecto, con una población degenerada, comprometida desde el punto vista racial, acarreaba enorme perjuicio para la inmensa mayoría de la población brasileña, que en esos términos se veía marginalizada. La europeización de las costumbres y la perspectiva del emblanquecimiento de la población brasileña, intensificada con el proceso inmigratorio, alejaba las posibilidades de convivencia con aquellos que un día fueron cautivos, esclavizados y subordinados (Marques, 1994; Souza Campos, 2003).

\section{EXCLUIDAS DE LA HISTORIA: "AMAS- DE-LEITE, BABÁS, MÃES PRETAS"}

El panorama histórico-cultural de la sociedad brasileña, las relaciones entre blancos y negros, develan las intenciones de ese artículo. La matriz teórica de la medicina eugénica, así como las interpretaciones médicas acerca de la degeneración de la raza, fueron decisivas para la eliminación de una de las más tradicionales prácticas culturales del Brasil, realizada por mujeres negras, llamadas amamantadoras, mujeres que trabajaban como cuidadoras de niños, sobre todo, en el acto de amamantar.

Durante los períodos que antecedieron a la instauración del régimen político republicano, la función social de las amas puede ser considerada como una de las primeras prácticas del cuidado formalmente ejecutadas en el Brasil. Aunque muchas mujeres negras fuesen esclavas, éstas trabajaban con las familias blancas como cuidadoras de niños. Cuidar de niños era parte del universo de las mujeres negras, habitualmente responsables por el amamantamiento y demás cuidados, que se extendían durante años, muchas veces, generaciones.

Familias señoriales mantenían entre sus esclavos mujeres negras que atendían a los hijos de su señor, como si fuesen sus "Madres de crianza", como eran llamadas, esas mujeres también eran parteras, incorporadas a la familia señorial como una esclava especial, casi siempre alforriada. 


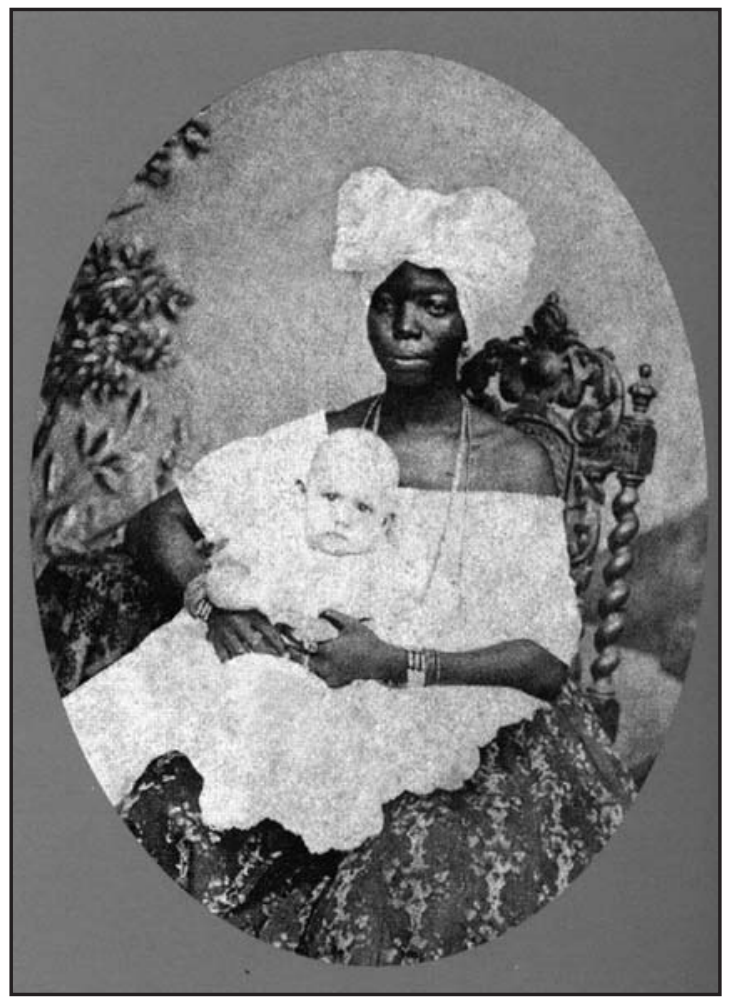

\section{Ama con niño}

Fuente: Fotografía de João Goston, c. 1870. Acervo Instituto Moreira Salles

Las fotografías que sirven de fuente para este estudio permiten considerar la existencia de una fuerte relación sentimental entre las mujeres negras y los niños blancos bajo sus cuidados. En contrapartida el análisis revela que lo mismo no sucedía con la mujer blanca en relación al niño negro. Monteiro Lobato, en uno de los cuentos que marcaron la literatura brasileña, presenta la historia trágica de una niña "negrita", de siete años, nacida en el espacio dedicado a los esclavos de una familia señorial y su relación con la señora, una mujer blanca y mala.

En uno de los pasajes, el autor retrata el sarcasmo original, el refinamiento en la crueldad ejecutado por la señora, develando la naturalidad del comportamiento inhumano. Al final del cuento la niña muere sin piedad, mas la muerte le parece un alivio, un aliento:

Cocres: mano cerrada con rabia y nudos de los dedos que cantan en la cabeza del paciente. Jalones de oreja: torcidas, despegar del pabellón de la

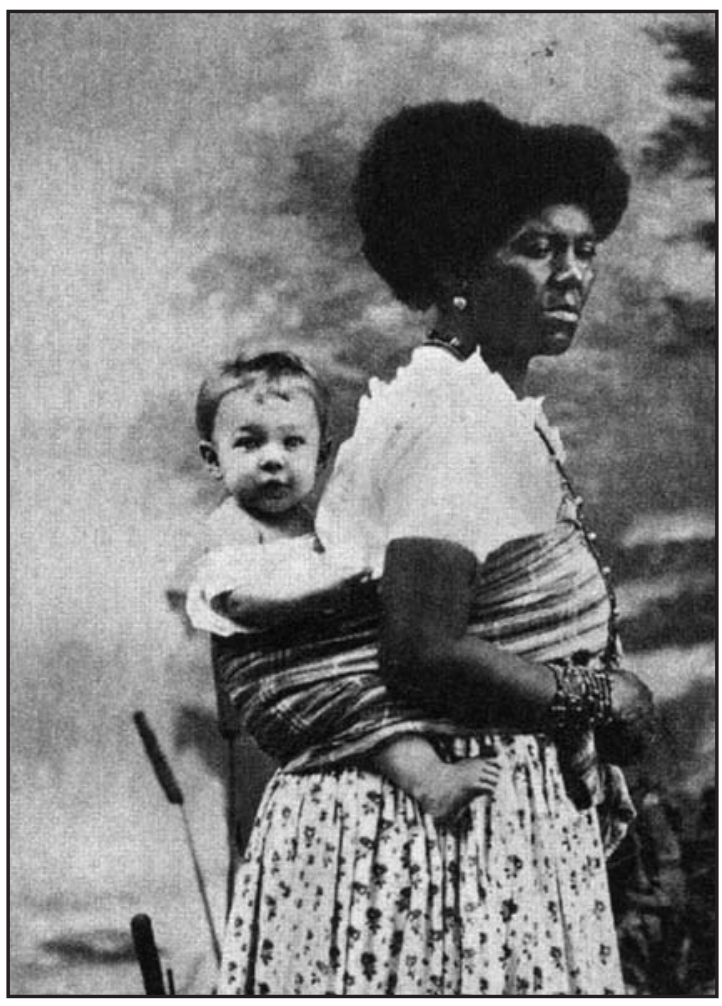

\section{Negra con niño}

Fuente: Fotografía de Rodolpho Lindemann. Colección Apparecido Jannir Salatini

oreja, con las dos manos, el sacudido. La gama entera de los pellizcones: del menudo, con la punta de la uña, la torcida del ombligo, equivalente al jalón de oreja. La paliza: una secuencia de lapos, cachetadas, puntapiés y puñetes. Divertidísimo! La vara de membrillo, flexible, cortante: para que duela suave nada mejor! (Lobato, 2000)

Diametralmente opuestas, las imágenes que se establecían entre las amamantadoras, niñeras y madres negras en relación a los niños blancos, reflejan una sensibilidad indiscutible, permitiendo suponer que había lugar genuino para el establecimiento de verdaderas relaciones afectivas entre personas con posiciones jerárquicamente muy distintas. Deiab (2005) identifica que en los anuncios de compra y venta de esclavos, publicados en periódicos de las grandes ciudades brasileñas como Salvador, Rio de Janeiro, Recife y São Paulo, la habilidad en el trato de niños era elemento que se destacaba, revelando que este cuidado extremo era esperado y deseado por las familias. 
Freyre (1999, p. 331), evoca la importancia que esas mujeres negras, las negras viejas y madres negras, ejercieron tanto en el ámbito del cuidado, atendiendo a niños y familias en el Brasil colonial, como en la formación de la cultura brasileña. Por intermedio de esas "negras viejas", "amas del niño", como las identifica el autor, el legado cultural de las tradiciones y folklores nacionales fueron preservados y añade “...la ama negra hace muchas veces con las palabras lo mismo que con la comida: las tritura, les quita las espinas, los huesos, las durezas, dejando sólo para la boca del niño blanco las sílabas blandas (...) las Antonias pasaron a llamarse Dondons, Toninhas, Totonhas; las Teresas, Tetés; los Manueles, Nezinhos, Mandus, Manés; los Franciscos, Chico, Chiquinho, Chicó; los Pedros, Pepés; los Albertos, Bebetos, Betinhos...”.

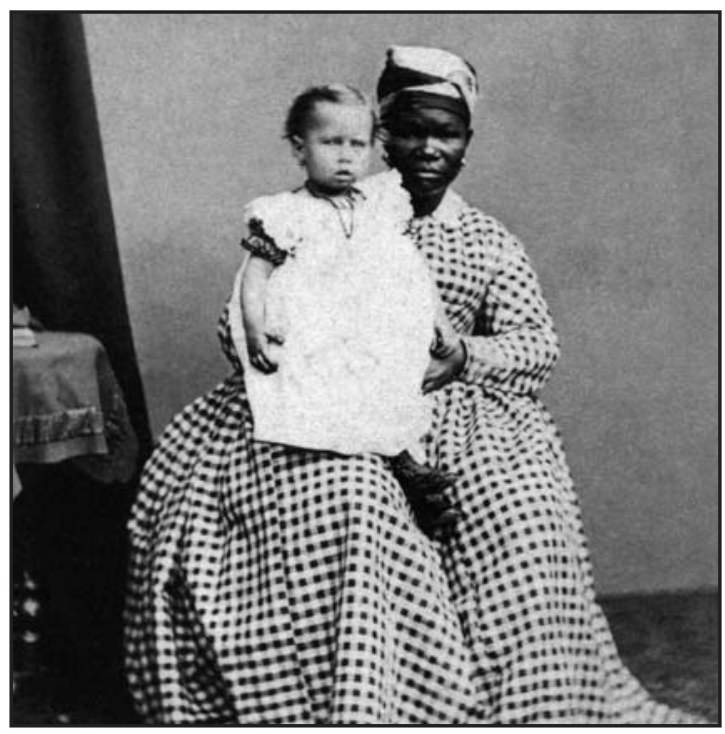

Negra con niño

Fuente: The London Stereoscopic and photographic Company. Colección Emanoel Araújo

El papel social desempeñado por las que amamantaban invadía la esfera de la vida privada. Además de mantener saludables a los hijos de las señoras blancas, favorecían la manutención del casamiento, pues al ocuparse del niño, la amamantadora permitía a la esposa permanecer junto al marido, así como satisfacer las demandas sociales y sexuales de la pareja - usadas por las mujeres como estrategia para mantener sus matrimonios y a sus hombres alejados de las negras, mulatas y de las mujeres de la tierra, las indias.

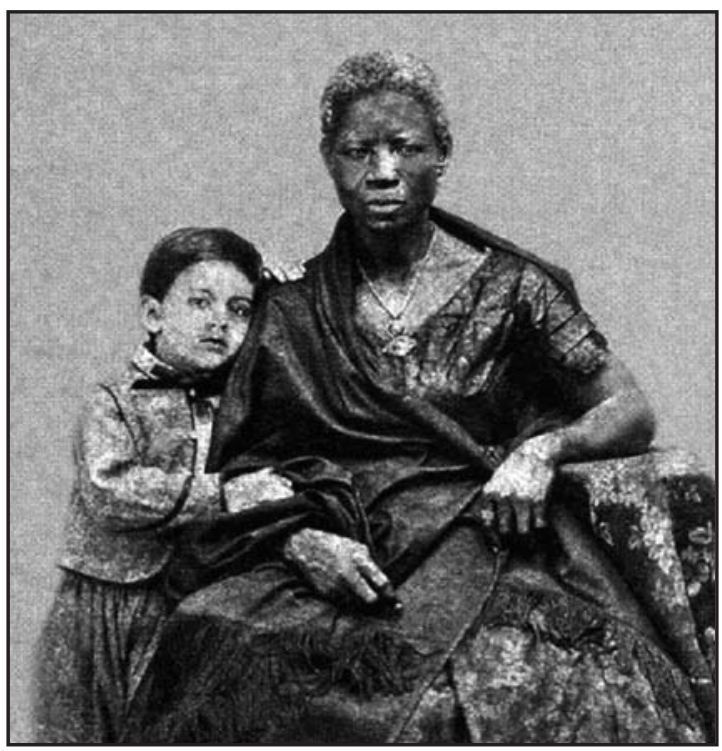

Joaquim Gomes Leal con la amamantadora Mônica, Pernanbuco

Fuente: Villela, C. 1860. Fundación Joaquim Nabuco, Recife.

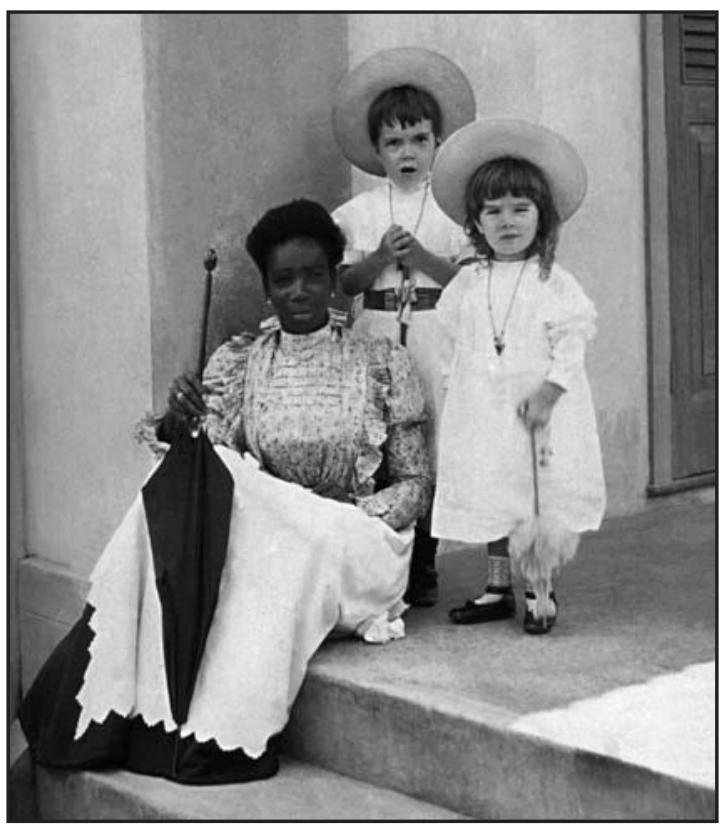

Olga y Stella haciendo pose con la niñera

Fuente: Fotógrafo no identificado. C.1890. Colección George Ermakoff 
Incuestionables, las representaciones producidas en torno a la raza volvían natural la idea de inferioridad, circulada explícitamente, como algo consensual. Para los médicos, que se orientaban por los dogmas de la medicina eugénica, la inmensa mayoría de la población brasileña era mentalmente atrasada, no poseyendo "el poder del raciocinio", debiendo ser guiada por la razón de quien sabía raciocinar.

Las representaciones derivadas de las teorías eugénicas ampliaban el espectro imaginativo en torno de las representaciones del negro, en este sentido, las relaciones sociales inter-étnicas eran interpretadas como despreciables, comprometedoras, mereciendo ser evitadas. Los significados resultantes generaron situaciones que perfeccionaban las prácticas segregacionistas, prejuiciosas, como ejemplifica el refrán popular de la época, que simboliza el discurso de la intolerancia racial: "los que nacen como los suyos no se degeneran".

En este sentido, el establecimiento de normas para reglamentar la vida social de las poblaciones ampliaba considerablemente el campo de acción de los profesionales del área de la salud, que se expandía. En el sentido de controlar acciones humanas, instruirlas para el "mejoramiento progresivo de la especie", las intervenciones médico sanitarias rechazaban las prácticas tradicionales, culturales, ejercidas desde la fase tribal de la historia de la enfermería (Souza Campos, 2007).

El cumplimiento de las órdenes médicas alrededor del destete también atendía a las demandas del creciente mercado de la leche pasteurizada. La modernidad de los productos industrializados, así como su uso, significaba pertenencia, status social, provocando al mismo tiempo la sensación de distanciamiento de costumbres y tradiciones consideradas arcaicas, anticuadas, en el caso, impuras (Rezende, 1998).

Para muchos, la contrariedad de las normas médicas implicaba una natural comprobación de inferioridad, incapacidad e incivilidad. El discurso médico, transformado en práctica cotidiana, afirmaba que las que amamantaban transmitían caracteres degenerativos de la raza negra al niño blanco durante el amamantamiento. Las orientaciones médicas que impidieron el trabajo de esas mujeres, también fueron simbólicamente utilizadas para establecer distinciones sociales. Con la difusión del destete, las familias que mantenían la práctica, permitiendo que sus hijos fuesen amamantados por amamantadoras negras, eran desprestigiadas socialmente, lo que no ocurría en los períodos anteriores.

\section{CONCLUSIÓN}

Conforme señala Chartier (1991, p. 17), las representaciones son construcciones que tienen fines específicos, por tanto, no pueden ser consideradas como discursos neutros, pero sí como productores de estrategias y prácticas que legitiman determinados proyectos y resalta “...aunque aspiren a la universalidad [las representaciones] son siempre determinadas por los intereses de un grupo que las forja".

De este modo, es posible decir que las determinaciones raciales y su utilización en el Brasil contribuyeron a la legitimación del discurso científico, oriundo de la medicina, que desautorizó a la práctica del amamantamiento realizada por mujeres negras, trabajadoras esclavas a quienes en esta investigación se las considera como las primeras cuidadoras del Brasil.

Remontarse a ese pasado y analizarlo a partir de los presupuestos de la cultura de los cuidados, implica no sólo rescatar experiencias vividas a lo largo del tiempo de la historia, sino develar prácticas de cuidar cuya función primordial consistía en la convivencia y cuidado integral al niño, del parto al amamantamiento, y después, actuando en la higiene, alimentación y reposo, actividades propias del arte del cuidado.

El trabajo realizado por amamantadoras en el Brasil, testimoniado por las fotografías, así como los usos sociales de esas imágenes, permiten considerar que la historia de la enfermería brasileña tiene su origen en las acciones de las mujeres negras cuidadoras de niños. Las vinculaciones antropológicas de la familia, como estructura social, destacan a esas mujeres como esenciales, afectiva y socialmente, reconocidas por la prontitud de sus cuidados.

Así, esta reflexión entiende que la escritura de la historia puede, estratégicamente, forjar acontecimientos, reducir intensidades y movimientos, manipular los hechos, crear mitos y memorias. La crítica histórica, que se origina de la problematización e interpretación del pasado, debe hacer emer- 
ger experiencias vividas por hombres y mujeres, ilustres e innominados.

El imaginario social construido alrededor de la historia de la enfermería brasileña logró desterrar de la memoria las experiencias y el ejercicio de su trabajo con las familias señoriales. La memoria de las mujeres negras del Brasil, cuidadoras de niños, parteras, nodrizas, llamadas "madres de crianza", resistieron a los imperativos de la escritura oficial de la historia y de la historia de la enfermería. Evocar la memoria de esas mujeres pretendió develar aspectos esenciales de la función social de las cuidadoras negras, así como la construcción de su imagen en la sociedad brasileña a lo largo de su proceso histórico.

\section{BIBLIOGRAFÍA}

- Barreira, IA. (1997) Os Primórdios da Enfermagem Moderna no Brasil. Escola Anna Nery - Revista de Enfermagem 1, 16176.

Carrijo, AR. (2007) Registros de uma Prática: anotações de enfermagem na memória de enfermeiras da primeira escola nightingalena no Brasil. Dissertação (Mestrado). Programa de Pós-Graduação em Enfermagem - Escola de Enfermagem da Universidade de São Paulo.

- Castro Santos, LAC; Faria, LR. (2004) A Cooperação Internacional e a Enfermagem de Saúde Pública no Rio de Janeiro e São Paulo. Horizontes 22, 123-50.

- Chartier, R. O Mundo como Representação. (1991) Revista Estudos Avançados 5, 173-91.

- Deiab, RA. (2005) A Memória Afetiva da Escravidão. Revista História Biblioteca Nacional 1, 36-40.

- Domingues, PJ. (2000) Uma História Mal Contada. Negro, racismo e trabalho no pós-abolição em São Paulo (18891930). SENAC, São Paulo.

Ermakoff G. (2004) O Negro da Fotografia Brasileira do Século XIX. G.Ermakoff Casa Editorial, Rio de Janeiro.

Espírito Santo, TB. (2007) Enfermeiras Francesas na Capital do Brasil. Dissertação (Mestrado). Programa de PósGraduação em Enfermagem - Escola de Enfermagem da Universidade de São Paulo.

- Freyre, G. (1999) Casa Grande \& Senzala. 35ª ed. Record, Rio de Janeiro/São Paulo.

- Hallam, J. (2000) Nursing the Image. Media, culture and professional identity. Routledge, London/New York.

- Holfbauer, A. (2000) Uma História do Branqueamento ou o Negro em Questão. Tese (Doutorado). Faculdade de Filosofia, Letras e Ciências Humanas - Universidade de São Paulo.

- Leninger, M. (1978) Transcultural Nursing: concepts, theories and practices. John Wiley and Sons, New York.

- Lobato, M. (2000) Negrinha. EDUSC, Bauru.

- Marques, VRB. (1994) A medicalização das raças. Médicos, educadores e discurso eugênico. Editora da UNICAMP, Campinas.

- Mott, ML. (1999) Revendo a História da Enfermagem em São Paulo. Cadernos Pagú 13, 327-55.
- Oguisso, T. (2007) Trajetória Histórica e Legal da Enfermagem. Manole, Barueri.

- Perrot, M. (1999) Mulheres Públicas. Edunesp, São Paulo.

- Porto, F; Amorim, W. (2007) História da Enfermagem Brasileira. Águia Dourada, Rio de Janeiro.

- Resende, MA. (1998) Amamentação e Trabalho na Escola de Enfermagem de São Paulo: um estudo sobre representações sociais. Tese (Doutorado). Programa de Pós-Graduação da Escola de Enfermagem da Universidade de São Paulo.

- Santos, GA. (2002) A Invenção do Ser Negro. Um percurso das idéias que naturalizaram a inferioridade dos negros. Educ/Pallas/Fapesp, São Paulo; Rio de Janeiro.

- Schwarcz LM. (1993) O espetáculo das raças. Cientistas, instituições e questão racial no Brasil (1870-1930). Companhia das Letras, São Paulo.

- Secaf, V; Villas-Boas, H. (2007) Enfermeiras do Brasil: história das pioneiras. Martinari, São Paulo.

- Silles, J. (1999) História de la Enfermería. Aguaclara, Alicante.

- Souza Campos, PF. (2003) Os crimes de preto Amaral. A representação da degenerescência em São Paulo. 1920. Tese (Doutorado). Programa de Pós-Graduação em História Universidade Estadual Paulista "Júlio de Mesquita Filho".

- Souza Campos, PF; Oguisso, T. (2006) Exclusión de mujeres negras. Su Representación en la Enfermeria Profesional. Revista Index de Enfermeria, Granada, 55, 27-31.

- Souza Campos, PF; Oguisso, T. (2007) Cultura dos Cuidados: mulheres negras e formação da enfermagem profissional brasileira. Cultura de los Cuidados. Revista de Enfermería y Humanidades 22, 33-39.

- Vaconcellos, MPC. (1995) Memórias da Saúde Pública. Hucitec Abrasco, São Paulo.

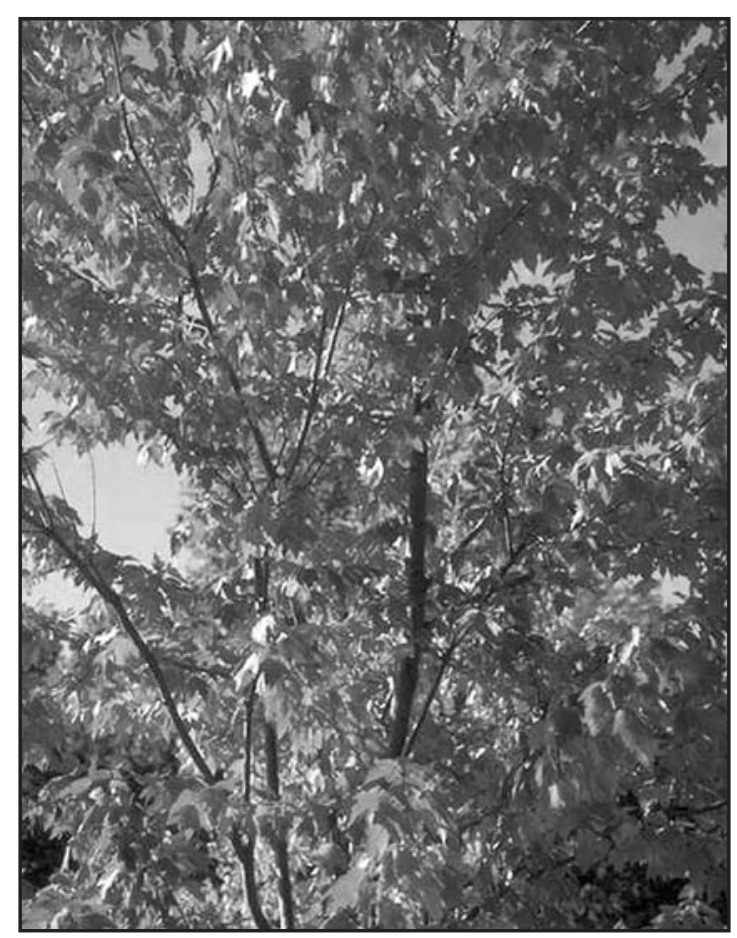

